\title{
Improvement of transient stability in an AC/DC system with synchronverter based HVDC
}

\author{
${ }^{1}$ Raouia. Aouini, ${ }^{2}$ Bogdan. Marinescu, ${ }^{1}$ Khadija. Ben Kilani, and ${ }^{1}$ Mohamed. Elleuch \\ ${ }^{1}$ University of Tunis El Manar, ENIT- L.S.E.-LR 11 ES 15-BP 37-1002 Tunis le Belvédère, Tunisia, \\ ${ }^{2}$ ENS-Cachan SATIE 61 Avenue du Président Wilson 94235 Cachan Cedex, France \\ Email: aaouinii @yahoo.com, bogdanmarinescu@yahoo.com, khadijakilani @yahoo.fr, \\ melleuch2005@yahoo.fr
}

\begin{abstract}
The HVDC emulation by the synchronverter concept is investigated in a realistic power system. A specific tuning method for the parameters of the regulators based on the sensitivity of the poles of the neighbor zone of the HVDC with the respect to the latter parameters is used. As consequence, not only the local performances of the HVDC link, but also overall transient stability of the AC zone in which the HVDC is inserted are improved. Extensive tests are provided using Matlab/Simulink implementation of the IEEE 9 bus/3 machines test system.
\end{abstract}

Index Terms - synchronverter, Synchronous generator/motor, SHVDC, transient stability, damping oscillatory modes.

\section{INTRODUCTION}

Due to environmental, technical and economical reasons, the installation of HVDC lines is favored in order to maximize the electric power transmission efficiency. As a result, the past five decades witnessed significant development in HVDC transmission systems [1]. Recently, rapid advancement was achieved in the field of power electronic devices such as Insulated Gate Bipolar Transistor (IGBT). That opens opportunities for the power industry via the utilization of HVDC based on Voltage Sourced Converters (VSC) with IGBT technology which is commercially known as HVDC Light $^{\mathrm{TM}}$ by ABB [2].

VSC-HVDC have enabled the interconnection of asynchronous networks, the connection of offshore wind farms, and the control of power flow especially for long distances such as the NorNed interconnection: the longest submarine DC cable between Norway and Netherlands. Nonetheless, other equally important HVDC applications concern complex AC interconnected system in order to enhance the power transmission capacity and meet the growing demand. These emerging applications gave rise to the co-existence of parallel HVDC/HVAC, and consequently, an increased level of $\mathrm{AC} / \mathrm{DC} / \mathrm{AC}$ converted power injected into AC networks.

Lately, the problem of VSC-HVDC transmission system's stabilization has attracted renewed attention in both power systems and control communities. Therefore several studies have shown that the methods of controlling HVDC converters have an impact on stability of the system in which the link is inserted [3]. Most control of a VSC-based HVDC system uses a nested-loop $d-q$ vector control approach based on the linear PI technology. The controller design is processed in the same manner for different operating conditions. In case of parameter uncertainties; changed operating conditions and faults; undesirable poorly damped or even unstable oscillations may result. More clearly, controller parameters yielding satisfactory damping and enhancing system's dynamic behavior for one operating condition may no longer provide sufficient damping for others [4]. Although, conventional controls are lack robustness and become difficult to implement especially for cases in which: different controllers are to be coordinated for a variety of operating conditions, and certain performance specifications have to be satisfied. Consequently, to overcome the undesired problems probably encountered by PI conventionally tuned controllers under operating conditions variations and to guarantee system stability, different robust controllers design [5] and adaptive control structures have been proposed [6].

Recently, in [7]-[13], the authors have proposed a different control method for which an inverter can be operated to mimic the behavior of a synchronous generator $(\mathrm{SG})$ and the resulting closed-loop has been called a synchronverter [7]. Since the operation of AC systems via SGs voltage/frequency regulation is rather well known [14], the synchronverter concept led to new applications. For example, in [13], a STATCOM controller was synthesized from the mathematical model of synchronous generators operated in a compensator mode. In [15], the synchronverter concept was adapted to converters of an HVDC transmission. The idea is a conceptual control strategy of the DC line, where the sending-end rectifier controls emulate a synchronous motor (SM), and the receiving end inverter emulates a SG, both along with their controls. This resulting Synchronverter based HVDC was called SHVDC. In this paper, the SHVDC system is tested in the IEEE 9 bus system. In the tuning stage, this control technique allows one to take into account dynamic specifications and swing information of the neighbour $\mathrm{AC}$ zone in term to better dynamic performances and to improve the transient stability of the neighbor AC zone of the HVDC link; and this fact is proven on a realistic power system. The rest of the paper is organized as follows: in Section II, the SHVDC structure is recalled. An analytic method to tune the parameters of the controllers of the SHVDC in order to meet the desired performances is given in Section III, while validation tests are presented in Section V. 


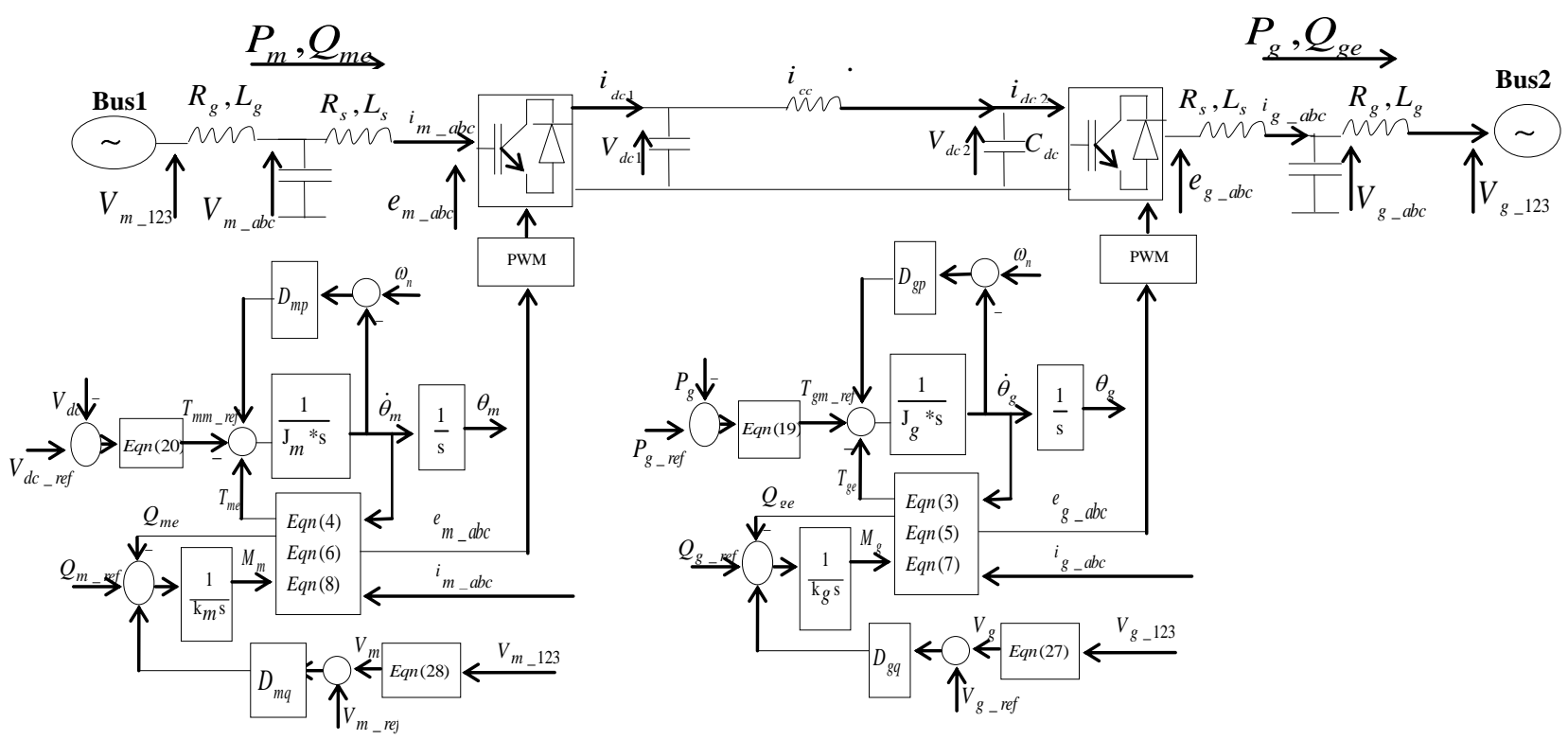

Fig. 1. Model of the SHVDC power and electronic parts [7]

\section{SYNCHRONVERTER BASED HVDC}

In this section, the converters of the HVDC line are designed to emulate synchronous machine. The synchronverter proposed in [7] is an inverter of which regulations are chosen such that the resulting closed-loop mimics the behavior of a conventional synchronverter generator (SG). For a complete DC system, a rectifier and an inverter are connected by a DC link as shown in Fig.1. Therefore, to provide an HVDC structure, another synchronverter working as a synchronous motor (SM) based on the same mathematic derivation is necessary. As a result, the DC power is sent from the SM to the SG. The resulting system in Fig. 1 is called Synchronverter High-Voltage Direct Current (SHVDC). On the figure, we depict:

(i) the power part of the SG/SM consists of the inverter/rectifier plus LC filter;

(ii) the controls are assured by the electronic part. VSC converter technologies shown in Fig. 1 are used. The overall structure is shown to be equivalent to a SG/SM with capacitor bank connected in parallel with the stator terminal.

The phase terminal voltage of the $\mathrm{SG}$ and $\mathrm{SM}$ are $\mathrm{V}_{\mathrm{g} \_\mathrm{abc}}=\left[\mathrm{V}_{\mathrm{ga}}\right.$ $\left.\mathrm{V}_{\mathrm{gb}} \mathrm{V}_{\mathrm{gc}}\right]^{\mathrm{T}}, \mathrm{V}_{\mathrm{m} \_\mathrm{abc}}=\left[\mathrm{V}_{\mathrm{ma}} \mathrm{V}_{\mathrm{gb}} \mathrm{V}_{\mathrm{gc}}\right]^{\mathrm{T}}$ respectively

$$
\begin{aligned}
& V_{g_{-} a b c}=-R_{s} i_{g_{-} a b c}-L_{s} \frac{d i_{g_{-} a b c}}{d t}+e_{g_{-} a b c}, \\
& V_{m_{-} a b c}=R_{s} i_{m_{-} a b c}+L_{s} \frac{d i_{m_{-} a b c}}{d t}+e_{m_{-} a b c} .
\end{aligned}
$$

where $i_{g-a b c}=\left[\begin{array}{lll}i_{g a} & i_{g b} & i_{g c}\end{array}\right]^{T}, i_{g-a b c}=\left[\begin{array}{lll}i_{g a} & i_{g b} & i_{g c}\end{array}\right]^{T}$, are respectively the stator phase currents of the SG and the SM, $\mathrm{L}_{\mathrm{s}}, \mathrm{R}_{\mathrm{s}}$ are, respectively, the inductance and the resistance of the stator windings and $\mathrm{e}_{\mathrm{g} \_\mathrm{abc}}=\left[\mathrm{e}_{\mathrm{ga}} \mathrm{e}_{\mathrm{gb}} \mathrm{e}_{\mathrm{gc}}\right]^{\mathrm{T}}, \mathrm{e}_{\mathrm{m} \_\mathrm{abc}}=\left[\mathrm{e}_{\mathrm{ma}} \mathrm{e}_{\mathrm{mb}}\right.$ $\left.\mathrm{e}_{\mathrm{mc}}\right]^{\mathrm{T}}$ are respectively the back emf of the SG and the SM.
As shown in Fig .1, controllers include the mathematical model of a three-phase round-rotor synchronous machine described by

$$
\begin{gathered}
\ddot{\theta}_{g}=\frac{1}{J_{g}}\left(T_{g m}-T_{g e}-D_{g p} s \theta_{g}\right), \\
\ddot{\theta}_{m}=\frac{1}{J_{m}}\left(T_{m e}-T_{m m}-D_{m p} \dot{\theta}_{m}\right), \\
T_{g e}=M_{g}<i_{g_{-} a b c}, \tilde{\sin } \theta_{g}>, \\
T_{m e}=M_{m}<i_{m_{-} a b c}, \tilde{\sin } \theta_{m}>, \\
e_{g_{-} a b c}=M_{g} s \theta_{g} \sin \theta_{g}, \\
e_{m_{-} a b c}=M_{m} s \theta_{m} \sin \theta_{m}, \\
P_{g}=M_{g} s \theta_{g}<i_{g_{-} a b c}, \sin \theta_{g}>, \\
Q_{g e}=-M_{g} s \theta_{g}<i_{g_{-} a b c}, \operatorname{cõs} \theta_{g}>, \\
Q_{m e}=M_{m} s \theta_{m}<i_{m_{-} a b c}, \tilde{c o s} \theta_{m}>, \\
P_{m}=M_{m} s \theta_{m}<i_{m_{-} a b c}, \sin \theta_{m}>.
\end{gathered}
$$

where

$\mathrm{T}_{\mathrm{gm}}$ and $\mathrm{T}_{\mathrm{mm}}$ are, respectively, the mechanical torque applied to the rotor of the SG and the SM.

$\mathrm{T}_{\mathrm{ge}}$ and $\mathrm{T}_{\mathrm{me}}$ are, respectively, the electromagnetic torque applied to the rotor of the SG and the SM.

$\theta$ is the rotor angle, $\mathbf{J}_{\mathrm{g}}$ and $\mathbf{J}_{\mathrm{m}}$ are the combined moment of inertia of generator and turbine.

$\mathrm{s}=\mathrm{d} / \mathrm{dt}$ is the derivation operator.

$P_{g}$ (respectively $P_{m}$ ) and $Q_{g}$ (respectively $Q_{m}$ ) are the active and the reactive power, respectively, of the $S G$ (respectively of the $\mathrm{SM})$.

$M_{g}$ and $M_{m}$ are, respectively, the field excitation of the SG and the SM.

The equations of $\sin \theta$ and $\cos \theta$ are 


$$
\begin{aligned}
\sin \theta & =\left[\sin \theta \sin \left(\theta-\frac{2 \pi}{3}\right) \sin \left(\theta+\frac{2 \pi}{3}\right)\right]^{T}, \\
\cos \theta & =\left[\cos \theta \cos \left(\theta-\frac{2 \pi}{3}\right) \cos \left(\theta+\frac{2 \pi}{3}\right)\right]^{T} .
\end{aligned}
$$

The operator $<\ldots, .>$ denotes the conventional inner product in $\mathbb{R}^{3}$.

The SHVDC given in Fig. 1 is connected to the grid via the impedance $\left(\mathrm{L}_{\mathrm{g}}, \mathrm{R}_{\mathrm{g}}\right)$ such that

$$
\begin{aligned}
& V_{g_{-} a b c}=\frac{1}{C_{f} s}\left(i_{g_{-} a b c}-i_{g_{-} 123}\right), \\
& i_{g_{-} 123}=\frac{1}{\left(R_{g}+L_{g} s\right)}\left(V_{g_{-} a b c}-V_{g_{-} 123}\right), \\
& V_{m_{-} a b c}=\frac{1}{C_{f} s}\left(i_{m_{-} 123}-i_{m_{-} a b c}\right), \\
& i_{m_{-} 123}=\frac{1}{\left(R_{g}+L_{g} s\right)}\left(V_{m_{-} 123}-V_{m_{-} a b c}\right) .
\end{aligned}
$$

To mimic the droop of the SG, the following frequency droop control loop is proposed

$$
\begin{aligned}
& T_{g m}=T_{g m-r e f}+D_{g p}\left(\omega_{n}-s \theta_{g}\right), \\
& T_{m m}=T_{m m-r e f}+D_{m p}\left(\omega_{n}-s \theta_{m}\right) .
\end{aligned}
$$

$\mathrm{T}_{\mathrm{gm} \_ \text {ref }}$ is the mechanical torque applied to the rotor of the $\mathrm{SG}$ and it is generated by a PI controller as shown in Fig. 1 to regulate the real power output $P_{g}$. In the SM case, $\mathrm{T}_{\mathrm{mm} \_ \text {ref }}$ is generated by a DC voltage control for power balance.

$$
\begin{gathered}
T_{m m-r e f}=\left(k_{p_{-} v d c}+\frac{k_{i_{-} v d c}}{s}\right)\left(V_{d c_{-} r f}-V_{d c 1}\right), \\
T_{g m_{-} r e f}=\left(k_{p_{-} p_{g}}+\frac{k_{i_{-} p_{g}}}{s}\right)\left(P_{g}-P_{g_{-} r f}\right) .
\end{gathered}
$$

The reactive power $\mathrm{Q}_{\mathrm{gm}}$ (respectively $\mathrm{Q}_{\mathrm{mm}}$ ) is controlled by a voltage droop control loop using a voltage droop coefficient $\mathrm{D}_{\mathrm{gq}}$ (respectively $\mathrm{D}_{\mathrm{mq}}$ ), in order to regulate the field excitation $\mathrm{M}_{\mathrm{g}}$ (respectively $\mathrm{M}_{\mathrm{m}}$ ), which is proportional to the voltage generated.

$$
\begin{gathered}
M_{g}=\frac{1}{k_{g} s}\left(Q_{g m}-Q_{g e}\right), \\
Q_{g m}=Q_{\mathrm{g} \_ \text {ref }}+D_{g q}\left(V_{g_{-} \text {ref }}-V_{g}\right), \\
M_{m}=\frac{-1}{k_{m} s}\left(Q_{m m}-Q_{m e}\right), \\
Q_{m m}=Q_{\mathrm{m} \_ \text {ref }}+D_{m q}\left(V_{m_{-} r e f}-V_{m}\right) .
\end{gathered}
$$

where $\mathrm{V}_{\mathrm{g}}$ (respectively $\mathrm{V}_{\mathrm{m}}$ ), is the output voltage amplitude is computed by:

$$
\begin{gathered}
V_{g}=\frac{2}{\sqrt{3\left(V_{g a} V_{g b}+V_{g a} V_{g c}+V_{g b} V_{g c}\right.}}, \\
V_{m}=\frac{2}{\sqrt{3\left(V_{m a} V_{m b}+V_{m a} V_{m c}+V_{m b} V_{m c}\right.}} .
\end{gathered}
$$

The circuit equations of the DC line (Fig. 1) are

$$
V_{d c 1}=\frac{1}{C_{d c} s}\left(i_{d c 1}-i_{c c}\right)
$$

$$
\begin{aligned}
& V_{d c 2}=\frac{1}{C_{d c} s}\left(i_{c c}-i_{d c 2}\right), \\
& i_{c c}=\frac{1}{L_{d c} s}\left(V_{d c 1}-V_{d c 2}-R_{d c} i_{c c}\right) .
\end{aligned}
$$

The AC and DC circuits are coupled by the active power relation

$$
\begin{gathered}
P_{d c 1}=V_{d c 1} i_{d c 1}, \\
P_{d c 2}=V_{d c 2} i_{d c 2}, \\
P_{d c 1}=P_{m}, \\
P_{d c 2}=P_{g} .
\end{gathered}
$$

\section{TUNING OF THE SHVDC PARAMETERS}

The SHVDC parameters should be tuned simultaneously and in a coordinated way such that the global stability performances of HVDC are ensured i.e:

- satisfy HVDC local dynamics. The SHVDC parameters are calculated to reach desired modes starting from HVDC specifications control. The connections between the dynamics of interest and the modes are based on the participations factors [16].

- enhance the transient stability of the neighboring AC system. This is done such that the dynamics of the neighbor zone are taken into account at the synthesis stage via the oscillatory modes. The gains of the SHVDC controllers are computed to damp these modes and thus to reduce the swing of the zone.

For this tuning, the SHVDC shown in is put into the feedback system structure presented in Fig. 2 where $\mathrm{H}(\mathrm{s})$ is the linear approximation of the system modeled by equations (1) to (34) with the exception of equations (19), (20), (21), (22), (24) and (26). All control parameters are grouped in the following diagonal matrix and tuned based on the following result.

$K(s, q)=\operatorname{diag}\left(D_{g p}, D_{m p}, K_{p_{-} \vee d c}, K_{i-V d c}, D_{g q}, D_{m q}, K_{p_{-} p_{g}}, K_{i-p_{g}}\right)$

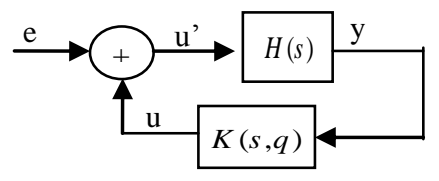

Fig. 2. Feedback system

Proposition [16]: The sensitivity of a pole $\lambda$ of the closedloop in Fig. 2 with respect to a parameter $q$ of the regulator $K_{i i}$ is

$$
\frac{\partial \lambda}{\partial q}=r_{\lambda} \frac{\partial K_{i i}(s, q)}{\partial q}
$$

where $r_{\lambda}$ is the residue of $H_{i i}(s)$ at pole $\lambda$.

Note that, for our case. (36), $\left.\frac{\partial K_{i i}(s, q)}{\partial q}\right|_{s=\lambda}=1$.

The contribution of each control gain in the shift of the pole is

$$
\lambda_{\imath}=\lambda_{i}^{0}+\sum_{j \in \Lambda} r_{i j} K_{j}
$$


where $\lambda_{i}^{0}$ is the initial (open-loop) location of the pole $\lambda_{i}$ and $r_{i j}$ is the residue of $H_{j j}(s)$ in $\lambda_{i}$. Finally, the pole placement is the solution of the following optimization problem

$$
\left\{K_{j}^{*}, j=1 \ldots 8\right\}=\underset{K_{j}}{\arg \min } \sum_{i}\left\|\lambda_{i}^{*}-\lambda_{i}\right\|^{2},
$$

where $\lambda_{i}$ is given by (38) [15].

\section{IEEE 9 BUS TEST SYSTEM}

The IEEE 9-bus system shown in Fig. 3 contains 3 generators, 5 lines, 3 loads and 3 two winding power transformers. The $100 \mathrm{~km} \mathrm{HVDC}$ cable link has a rated power of $200 \mathrm{MW}$ and a DC voltage rating of $\pm 100 \mathrm{kV}$. The rating of each generator is $600 \mathrm{MVA}$ and $20 \mathrm{kV}$. Each of the units is connected through transformers to the $100 \mathrm{kV}$ transmission line. The detailed system data is given in the appendix. The loads $\mathrm{L}_{1}, \mathrm{~L}_{2}$ and $\mathrm{L}_{3}$ are modeled as constant impedances.

\section{Simulations TeST}

This section deals with performances and robustness of the proposed control. Simulation tests are performed using MATLAB SiMULINK software. The tuned SHVDC parameters technique presented in Section III is tested and compared with the classic vector control which has a cascade structure with a current inner loop more rapid than the outer one. The two controllers are tuned to satisfy the same performance specifications.

\section{A. Local performances}

Table I (column 3) presents the desired location of modes $\lambda_{i}^{*}$ for each dynamic of interest. The optimal parameters $\mathrm{K}$ in the appendix were obtained with (39) solved for the desired locations in Table I. The response of SHVDC for the link in Fig. 3 with these tuned parameters is given in Fig. 4 in solid lines in comparison with the ones in dotted lines obtained with a classic vector control. Figs 4.a and 4.b show the responses of active and reactive powers to a +0.1 p.u step in $\mathrm{P}_{\mathrm{g} \_ \text {ref }}$ and to a 0.1 p.u step in $\mathrm{Q}_{\mathrm{g} \_ \text {ref.. }} \mathrm{A}$ good tracking of the active power reference and satisfying control specifications for both responses is observed. It is noted that better dynamic responses are provided with the new coordinated. Indeed, Fig. 5 illustrates the response to a step of -0.5 p.u in $\mathrm{P}_{\mathrm{g}_{-} \text {ref }}$ to test the performances of the controller to a sudden change in the direction of the transmitted power.

\section{B. Transient stability}

Fig. 6.a, b and c, respectively show the responses of the angular speed of generator G1, G2 and G3, to a three phase short circuit fault of $100 \mathrm{~ms}$ duration, occurring near G2. Again better dynamic performances are obtained with the proposed controller: the transient oscillations with the SHVDC control are more damped. The transient stability is assessed by the Critical Clearing Time (CCT), which is the maximum time duration that a short-circuit may act without losing the system capacity to recover to a steady-state (stable) operation.

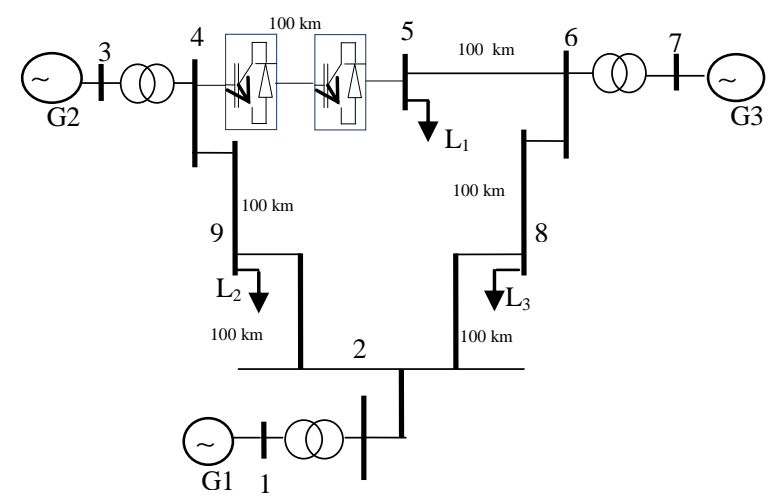

Fig. 3. Test power system

Table I

Desired modes meeting the HVDC specifications

\begin{tabular}{|c|c|c|c|}
\hline $\begin{array}{c}\text { Dynamics of } \\
\text { interest }\end{array}$ & $\lambda_{i}^{0}$ & $\lambda_{i}^{*}$ & $r_{\lambda_{i}^{0}}$ \\
\hline Voltage $\mathrm{V}_{\mathrm{m}}$ & -5.36 & -10 & -0.18 \\
\hline Voltage $\mathrm{V}_{\mathrm{g}}$ & 0.035 & -10 & -0.12 \\
\hline $\begin{array}{c}\text { Active Power } \\
\mathrm{P}_{\mathrm{m}}\end{array}$ & $1.69 \pm 5.07 \mathrm{i}$ & $-21 \pm 21.42 \mathrm{i}$ & $-0.08 \pm 0.06 \mathrm{i}$ \\
\cline { 2 - 4 } & $-2.78 \pm 18.89$ & $-21 \pm 21.42 \mathrm{i}$ & $-0.02 \pm 0.07 \mathrm{i}$ \\
\cline { 2 - 4 } & $-2.57 \pm 3.51$ & $-11 \pm 10 \mathrm{i}$ & $-0.05 \pm 0.08 \mathrm{i}$ \\
\cline { 2 - 4 } & $0.2 \pm 0.604 \mathrm{i}$ & $-13 \pm 14 \mathrm{i}$ & $-0.2 \pm 0.33 \mathrm{i}$ \\
\hline $\begin{array}{c}\text { Active Power } \\
\mathrm{P}_{\mathrm{g}}\end{array}$ & $-0.23 \pm 4.405$ & $-21 \pm 21.42 \mathrm{i}$ & -0.15 \\
\cline { 2 - 4 } & 0.001 & -50 & $0.002 \mathrm{i}$ \\
\hline $\begin{array}{c}\text { Reactive Power } \\
\mathrm{Q}_{\mathrm{m}}\end{array}$ & -5.36 & -10 & -0.18 \\
\hline $\begin{array}{c}\text { Reactive Power } \\
\mathrm{Q}_{\mathrm{g}}\end{array}$ & 0.035 & -10 & -0.12 \\
\hline
\end{tabular}

The obtained CCTs for a three-phase short-circuit occurring near each generator are presented in Table II for the classic vector control, and the proposed SHVDC control. We can see that the SHVDC control with tuned parameters improves the transient dynamics of the system and thus augments the transient stability margins of the neighbor network. This is due to the fact that the dynamics of the neighbour zone are taken into account at the synthesis stage via the oscillatory modes in Table I. The gains of the controllers are computed to damp these modes and thus to diminish the general swing of the zone and not only for the local HVDC dynamics.

Table II

Critical Clearing Times with both control strategies

\begin{tabular}{|l|l|l|l|}
\hline CCT (ms) & G1 & G2 & G3 \\
\hline SHVDC & 250 & 200 & 200 \\
\hline Classic vector control & 150 & 120 & 150 \\
\hline
\end{tabular}




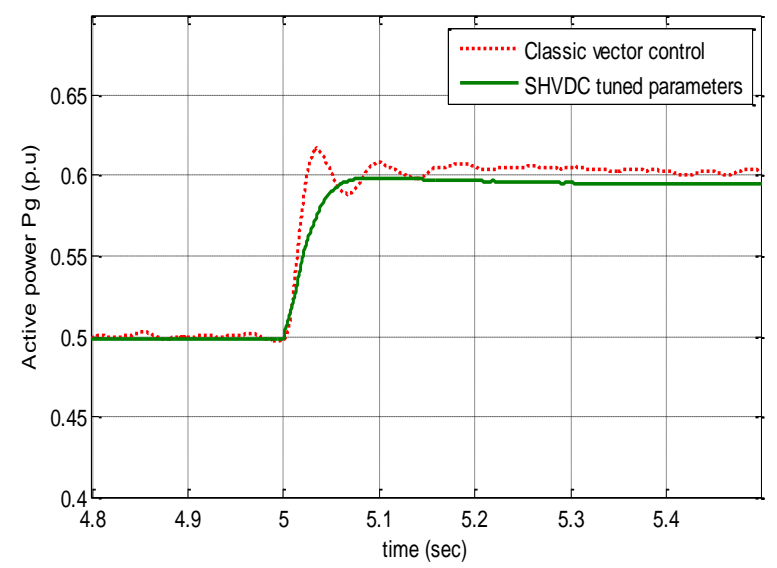

(a)

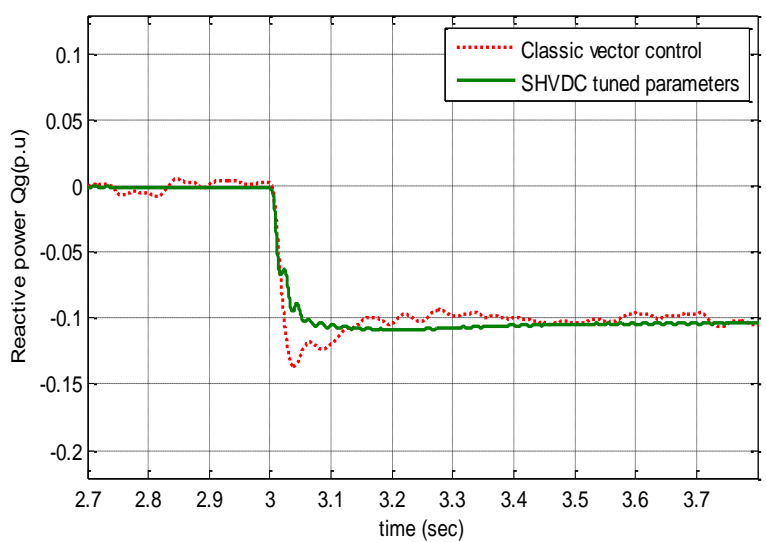

(b)

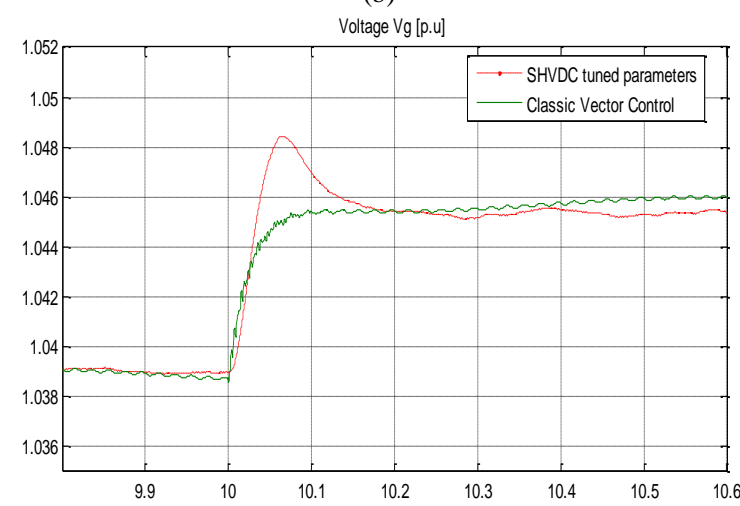

(c)

Fig.4. Responses of the IEEE 9 bus system (a)Response of Pg to a +0.1 step in Pg_ref (p.u) (a)Response of Qg to a -0.1 step in Qg_ref (p.u) (a)Response of Vg to a +0.1 step in Qg_ref (p.u)

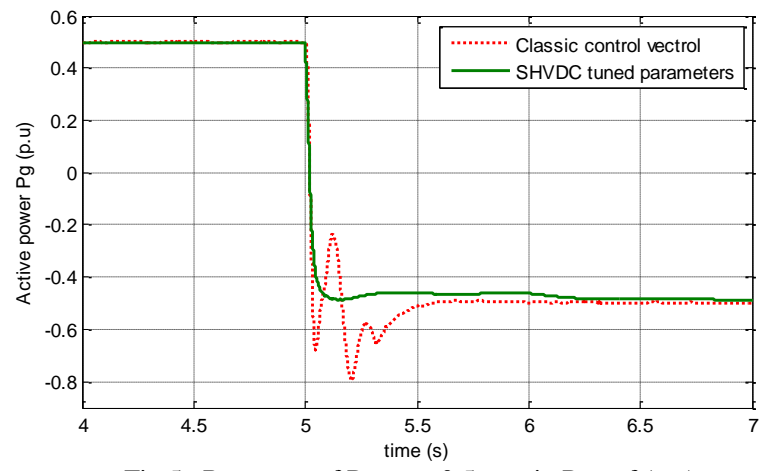

Fig.5. Response of Pg to a -0.5 step in Pg_ref (p.u)

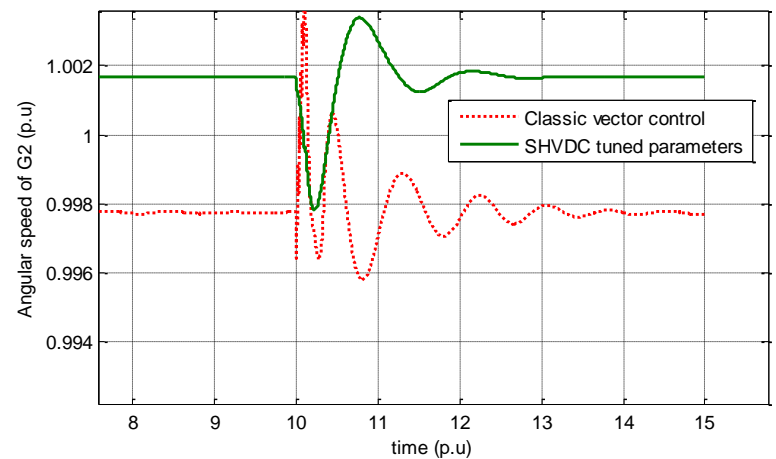

(a)

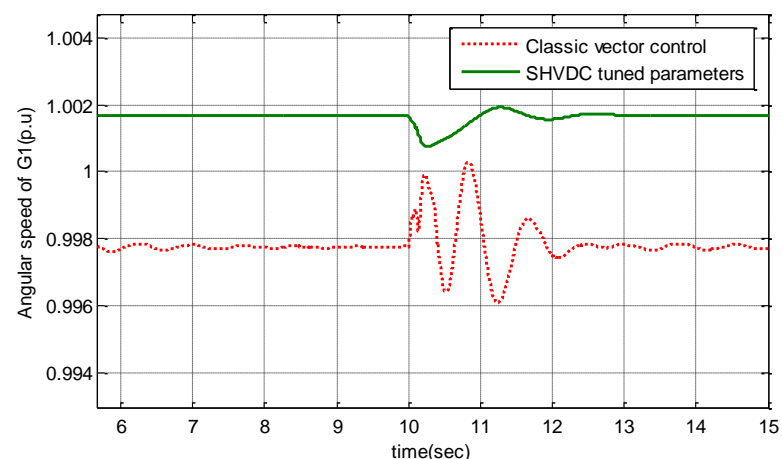

(b)

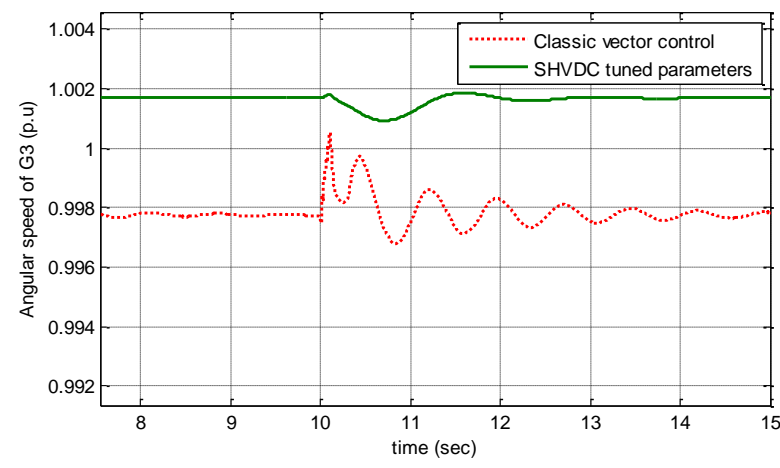

(c)

Fig.6. Responses of the angular speed to a $100 \mathrm{~ms}$ short circuit near to G2 (a)Angular speed of G2 (p.u)

(b)Angular speed of G1 (p.u)

(c)Angular speed of G3 (p.u) 


\section{Robustness against variation of the operating point}

As the synthesis of the SHVDC controller is based on the linear approximation as presented in Section III, robustness of performances against the variation of the operating point is required. Therefore, a new load flow setting is considered for the simulations. For example, the active power of load L1 is increased by $50 \mathrm{MW}$. The gains of the SHVDC controller are not recomputed and are thus the same as in the appendix. Fig. 7 gives the active power response to $\mathrm{a}+0.1$ step in $\mathrm{P}_{\mathrm{g} \_ \text {ref }}$ in this case. The latter is comparable with the one obtained in Fig. 4.a. In addition, the dynamic performance is better than the one obtained with the standard controller. This confirms the good robustness of the performances of the proposed controller against variation of operating conditions.

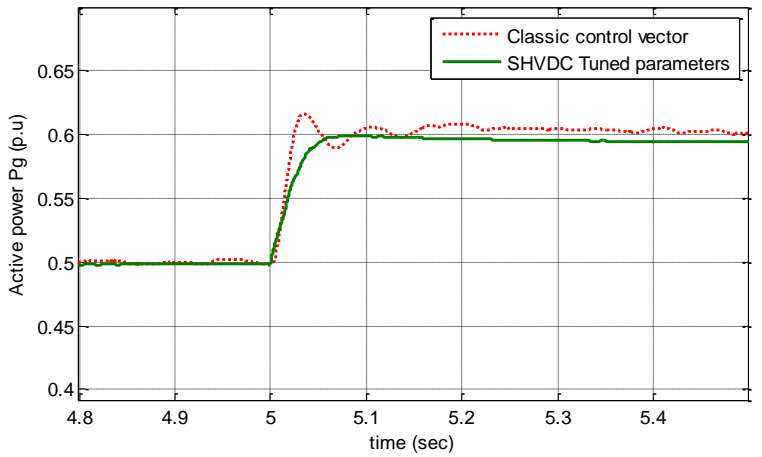

Fig.7. Response of Pg to a +0.1 step in Pg_ref (p.u) with a new operating point

\section{CONCLUSION}

A High Voltage Direct Current HVDC has been emulated using the synchronverter concept. A control strategy of the converters has been proposed based on a specific tuning method which uses, the sensitivity analysis of the system poles with respect to the control parameters. The control strategy has been validated on a realistic IEEE benchmark. More specifically, better results than with the standard vector control were obtained for the following points:

- Better dynamic performances (less overshoot and more damping) because this approach allows one to analytically take into account dynamic specifications at the tuning stage.

- Better stability margin of the neighbor zone for two reasons. First, swing information is directly taken into account at the synthesis stage in terms of the less damped modes of the neighbor zone and not only for the local HVDC dynamics as it is the case for the standard VSC control.

\section{REFERENCES}

[1] D. Velasco, C.L. Trujillo, and R.A. Pe na. Power transmission in direct current: Future expectations for Colombia. Renewable and Sustainable Energy Reviews, In Press, 2010.

[2] N.G. Hingorani. High-voltage DC transmission: a power electronics workhorse IEEE Spectrum, 33(4):6372.

[3] A.E. Hammad, J. Gagnon and D. McCallum, "Improving the dynamic performance of a complex AC/DC system by HVDC control modifications," IEEE Trans. Power Delivery, 1990, 5, (4), pp. 1934-1943.

[4] S. Ruihua, Z. Chao, L. Ruomei, and Z. Xiaoxin. VSCs based HVDC and its control strategy. In IEEE \{PES Transmission and Distribution Conference and Exhibition: Asia and Pacfic, pages 1\{6, 2005.

[5] H. Latorre, and M. Ghandhari, "Improvement of power system stability by using a VSC-HVDC, "Int. J. Electr. Power Energy Syst, 2011, 33, (2), pp. 332-339.
[6] N. Rostamkolai, A.G. Phadke, W.F. Long, and J.S. Thorp, "An adaptative optimal control strategy for dynamic stability enhacement of AC/DC power systems, " IEEE Trans. Power Syst., 1988, 3, (3), pp. 1139-1145.

[7] Q.-C. Zhong, and G.Weiss, "Synchronverters: Inverters that mimic synchronous generators," IEEE Trans. Ind. Electron., Apr. 2011, vol. 58, no. 4, pp. $1259-1267$.

[8] L. Zhang, L. Harnefors, and H.-P. Nee, "Power synchronization control of grid-connected voltage-source converters," IEEE Trans. Power Syst, May 2010, vol. 25 , no. 2 , pp. 809-820.

[9] H.-P. Beck, and R. Hesse, "Virtual synchronous machine, " in Proc. of the 9th International Conference on Electrical Power Quality and Utilisation (EPQU), 2007, pp. 1-6.

[10]J. Driesen, and K. Visscher, "Virtual synchronous generators," in Proc. of IEEE Power and Energy Society General Meeting, 2008, pp. 1-3.

[11] Y. Chen, R. Hesse, D. Turschner, and H.-P. Beck, "Improving the grid power quality using virtual synchronous machines," in 2011 International Conference on Power Engineering, Energy and Electrical Drives (POWERENG), 2011, pp. 1-6.

[12]M. Torres, and L. A. C. Lopes, "Frequency control improvement in an autonomous power system: An application of virtual synchronous machines," in 2011 IEEE $8^{\text {th }}$ International Conference on Power Electronics and ECCE Asia (ICPE \& ECCE), 2011, pp. 2188-2195.

[13]P-L. Nguyen, Q-C. Zhong, F. Blaabjerg, and J-M. Guerrero, " Synchronverter-based Operation of STATCOM to Mimic Synchronous Condensers", 2012 7th IEEE Conference on Industrial Electronics and Applications (ICIEA).

[14]P. Kundur, "Power system stability and control", Mc Graw-HillInc, 1994 [15] R. Aouini, B. Marinescu, K. Ben Kilani and M. Elleuch" Synchronverterbased Emulation and Control of HVDC transmission", accepted for publication in IEEE Trans. Power Systems, January 2015.

[16] G. Rogers, "Power System Oscillations", Kluwer Academic, 2000.

\section{APPENDIX}

$\mathrm{K}=[55 ; 46.4 ; 24.0 ; 28.5 ; 65.64 ; 58.069 ; 56.39 ; 25.11 ; 37.35]$.

Parameters of the classic vector control: current loop: $\mathrm{kp}=0.6, \mathrm{ki}=8$, reactive power control: $\mathrm{ki}=10$, active power control: $\mathrm{ki}=10$, DC voltage control: $\mathrm{kp}=10$, $\mathrm{ki}=10$.

Generators: Rated 600 MVA, $20 \mathrm{kV}$

$\mathrm{Xl}$ (p.u): leakage Reactance $=0.18, \mathrm{Xd}$ (p.u.): d-axis synchronous reactance $=$ 1.305, T'd0 (s): d-axis open circuit sub-transient time constant $=0.296, \mathrm{~T}^{\prime}{ }_{\mathrm{d} 0}$ (s): d-axis open circuit transient time constant $=1.01 ; \mathrm{Xq}$ (p.u): q-axis synchronous reactance $=0.053, \mathrm{Xq}$ (p.u): q-axis synchronous reactance $=$ $0.474, \mathrm{X}$ ' 'q (p.u): q-axis sub-transient reactance $=0.243$, T' 'q0 (s): q-axis open circuit sub transient time constant $=0.1$

$\mathrm{M}=2 \mathrm{H}(\mathrm{s})$ : Mechanical starting time $=6.4$

Governor control system : R (\%): permanent droop $=5$, servo-motor: $\mathrm{ka}=10 / 3$, ta $(\mathrm{s})=0.07$, regulation PID: $\mathrm{kp}=1.163, \mathrm{ki}=0.105, \mathrm{kd}=0$

Excitation control system : Amplifier gain: $\mathrm{ka}=200$, amplifier time constant: $\mathrm{Ta}(\mathrm{s})=0.001$, damping filter gain $\mathrm{kf}=0.001$, time constant te $(\mathrm{s})=0.1$

27th AC filter in AC system 1 \& 2: reactive power=18 MVAR, tuning frequency $=1620 \mathrm{~Hz}$, quality factor $=15$.

54th AC filter in AC system 1 \& 2: reactive power=22 MVAR, tuning frequency $=3240 \mathrm{~Hz}$, quality factor $=15$.

DC system: voltage $= \pm 100 \mathrm{kV}$, rated DC power $=200 \mathrm{MW}, \mathrm{Pi}$ line $\mathrm{R}=0.0139$

$\Omega / \mathrm{km}, \mathrm{L}=159 \mu \mathrm{H} / \mathrm{km}, \mathrm{C}=0.331 \mu \mathrm{F} / \mathrm{km}$, Pi line length $=150 \mathrm{~km}$, switching frequency $=1620 \mathrm{~Hz}, \mathrm{DC}$ capacitor $=70 \mu \mathrm{F}$, smoothing reactor: $\mathrm{R}=0.0251 \Omega$, $\mathrm{L}=8 \mathrm{mH}$.

Generator transformers Rated 400 MVA, 20/ 100 kV ,Coupling Delta/ Yg Primary resistance (p.u) $=0.002$, Primary inductance (p.u) $=0.12$.

Secondary resistance (p.u) $=0.002$, Secondary inductance $(p . u)=0.12$. Loads: PL1=300 MW, PL2=300 MW ; PL2= $300 \mathrm{MW}$

AC transmission lines: Resistance per phase $(\Omega / \mathrm{km})=0.03$, Inductance per phase $(\mathrm{mH} / \mathrm{km})=0.32$, Capacitance per phase $(\mathrm{nF} / \mathrm{km})=11.5$ 